\title{
Variety, Globalization, and Social Efficiency
}

\author{
W. Michael Cox \\ AND \\ RoY J. RUFFIN \\ Research Department \\ Working Paper 0806
}

Federal Reserve Bank of Dallas 


\title{
Variety, globalization, and social efficiency ${ }^{\diamond}$
}

\author{
W. Michael $\operatorname{Cox}^{\mathrm{a}, 1}$, Roy J. Ruffin ${ }^{\mathrm{b}, *}$ \\ ${ }^{a}$ Research Department, Federal Reserve Bank of Dallas, 2200 N. Pearl St., Dallas, TX, 75201 \\ Cox School of Business, Southern Methodist University, Dallas, TX, 75205 \\ ${ }^{b}$ Department of Economics, University of Houston, 4800 Calhoun, Houston, TX, 77204
}

\begin{abstract}
This paper puts recent work on the benefits of variety into the context of a more complete quantitative analysis of the Dixit-Stiglitz-Krugman model of monopolistic competition. We show how the gains from globalization are reflected in the increase in variety and the exploitation of economies of scale, and that the social efficiency question is quantitatively insignificant. These results follow from examining a Bertrand-Nash equilibrium that allows for a finite number of varieties to affect the elasticity of demand facing each firm. We develop a precise expression for per capita real income with any number of sectors where globalization increases productivity through economies of scale.
\end{abstract}

Keywords: Economies of scale; Variety; Globalization; Measurement of real income

JEL Classification: F12; L11; D60

\section{Introduction}

Paul Samuelson (1948, p. 484; 1967, p. 426) was fond of pointing out that the "privilege of being able to buy a vast array of goods at low prices cannot be overestimated." Michael Cox and Richard Alm (1998) showed that U.S. consumers enjoy 790 different magazines, 285 styles of running shoes, 340

$\diamond$

We want to thank Bill Ethier, Robert Feenstra and Edwin Lai for valuable comments.

The views in this paper are those of the authors and not necessarily the views of the Federal Reserve Bank of Dallas or the Federal Reserve System.

* Corresponding author. Tel: 713743 3827; fax: 7137433798.

Email addresses: wm.cox@dal.frb.org (W. M. Cox); rruffin@uh.edu (R. J. Ruffin).

${ }^{1}$ Tel: 214922 5150; fax: 2149225306. 
different breakfast cereals, 185 various television channels, 1212 models of vehicles and more - in large part owing to the vast expansion of variety brought by globalization. It is difficult to imagine that these customers would have been only marginally better off had they all just driven a white Chevrolet, ate Wheaties, read Business Week, and watched the Public Broadcasting System. It is here that the theory of monopolistic competition becomes exceedingly useful: to get a handle on the value of variety.

In a constant-elasticity-of-substitution (CES) utility function, the smaller is the elasticity the higher is the value placed on variety. The empirical aspects of estimating elasticities of substitution have been brought out in papers by Robert Feenstra (1994), Mark Bils and Peter Klenow (2001), Christian Broda and David Weinstein (2006), and Feenstra and Hiau Kee (2008), among others. Broda and Weinstein (2006) estimated that the increase in the number of available varieties due to international trade from 1972 to 2001 was valued by U.S. consumers at 2.6 percent of their real income. Other researchers have found larger estimates of the gains from variety.

We do not here try to improve on these estimates. Rather, by a more faithful quantitative representation of the simplest model, we try to make more evident how economies of scale and elasticities of substitution fit into the standard model of monopolistic competition. 
It will be recalled that there are two approaches to monopolistic competition: the love-of-variety approach (Avinash Dixit and Joseph Stiglitz, 1977; Paul Krugman, 1981) that approximates the solution with an elasticity of demand equal to the constant elasticity of substitution; and the Kelvin Lancaster (1980) approach with heterogeneous consumers, each of whom had a single mostpreferred variety. The Lancaster approach had the nice feature that it generated higher demand elasticities with a larger market, because each consumer would be closer to her most-preferred variety. However, it is very difficult to analyze (Elhanan Helpman and Krugman, 1985). Thus, we present a fresh analysis of the Dixit-Stiglitz-Krugman (DSK) model of monopolistic competition in which the elasticity of demand facing each firm is endogenous. DSK and others have used the approximation that the number of varieties does not affect the elasticity of demand facing each firm. We use the Bertrand-Nash equilibrium concept to have a two-way street between the number of varieties and the elasticity of demand in comparing equilibrium outcomes. The model is almost as simple as the DSK approximation, but allows us to focus on the role of economies of scale.

Recent work by Catia Montagna (2001), Marc Melitz (2003) and Feenstra and Kee (2008) emphasizes the importance of firm heterogeneity in determining the impact of globalization on productivity. Their set up is distinguished by a continuum of firms wherein the elasticity of demand facing each firm equals the elasticity of substitution. In their work, globalization causes the exit of lower 
productivity firms, resulting in an increase in aggregate productivity. This approach, however, abstracts from one possible feature whereby globalization can affect welfare - through the exploitation of economies of scale made possible by larger markets.

Economies of scale are a two-edged sword. The greater are the economies of scale, the fewer are the number of varieties and the larger is the gain in productivity from globalization; the smaller are the economies of scale, the greater is variety and the smaller is the gain in productivity. By having a model with variable demand elasticities this tension is nicely captured. We will return to this theme in the sequel.

We look at three theoretical questions: (1) What are the relative roles of variety and per capita output in determining per capita utility? (2) What are the productivity gains from globalization due to economies of scale? (3) How great of a departure from social efficiency prevails in a world of free entry and variety? We show that by dropping the approximation that DSK and others have used it is possible to give interesting answers to the above questions. For example, to estimate per capita utility it is only necessary to look at per capita incomes in each sector, the relative importance of each sector, and estimates of the substitution parameter in that sector. Broda and Weinstein (2006) use U.S. import shares; but the model itself suggests that the appropriate weights are GDP shares. 
Section II presents the analysis of demand, which simply reprises the work of Helpman and Krugman (1985, pp. 117-120), who oddly do not apply the analysis to the model. Section II also presents a new graphical analysis of the model of monopolistic competition that parallels Krugman's pioneering treatment. Section III then solves for the exact solutions to the relevant variables and shows that the ratio of real income to measured per capita GDP increases with the size of the economy and the preference for variety. The result easily generalizes to an economy with many sectors. Section III also shows that per capita consumption of each variety still falls as the population rises and more varieties are introduced. This result had to hold in Dixit and Stiglitz (1977) and Krugman (1981) because their approximation required a constant output for each firm. Section IV looks at the issue of globalization, and shows how international trade increases real income faster than measured GDP, depending on the relative size of the economy and, once again, the preference for variety. We find that the simple DSK model used here likely gives a gain from trade that is an order of magnitude too large, suggesting that modifications must be made for deeper applications. The DSK approximation that the size of each firm is negligible compromises the question of the socially efficient number of firms. We agree with the spirit of Dixit and Stiglitz (1977) that excessive entry is not a problem, but their claim that the market equilibrium is characterized by insufficient entry is not supported by our analysis. ${ }^{2}$ We show that under the assumption of a CES

\footnotetext{
${ }^{2}$ Mankiw and Whinston (1986) showed that in a Cournot model with free entry there is excessive entry, but
} 
utility function, the socially optimal number of firms falls short of the market equilibrium but only by a fraction that measures the substitutability of the different varieties - so it is essentially a non-issue. This analysis is presented in Section V.

\section{The model}

Let there be a homogeneous population of $\mathrm{L}$ agents, each with the same symmetric utility function over $n$ varieties of some differentiated good, such as the automobile or cereal industries. Each variety of the good is produced by the same production function, $l=\alpha+\beta x$, where $l$ and $x$ and labor input and output respectively for fixed $(\alpha)$ and variable $\operatorname{costs}(\beta x)$. Labor is completely mobile between varieties. We let labor be the numeraire, so the wage $w=1$. Each consumer or agent has the same symmetrical constant-elasticity-of-substitution

utility function, $u=\left(\sum_{i} c_{i}^{\theta}\right)^{\frac{1}{\theta}}$, with $\theta$ between 0 and 1 . Thus, every variety faces the same demand and same costs. The elasticity of substitution is $\sigma=1 /(1-\theta)$, and so must always exceed unity. The parameter $\theta$ is an inverse measure of the preference for variety among substitute varieties. The demand for each variety is then

$$
c_{i}=\frac{p_{i}^{\frac{1}{\theta-1}}}{\sum_{j} p_{j}^{\frac{\theta}{\theta-1}}},
$$

the analysis was qualitative rather than quantitative. 
where income is unity and $p_{\mathrm{j}}$ is the price of each variety. Since the term $(1-\theta) / \theta$ appears in so many equations, we shall call it our measure of the preference for variety. We assume that the $\mathrm{i}^{\text {th }}$ firm considers all other prices fixed, as in Bertrand. The firm would thus calculate the numerical value of the elasticity of demand for its variety $i$ as:

$$
\varepsilon_{i}=\sigma-(\sigma-1) \frac{p_{i}^{1-\sigma}}{\sum_{j} p_{j}^{1-\sigma}} .
$$

There is no necessity to assume that $n$ is so large that $\varepsilon_{i}=\sigma$, as in Dixit and Stiglitz (1977), Krugman (1981) or Dixit and Victor Norman (1980). With equal costs and equal demands, in a symmetrical Nash equilibrium all prices will be $p_{\mathrm{i}}=p$, so in that equilibrium the elasticity of demand facing each firm will simply be:

$$
\varepsilon(n)=\sigma-\frac{(\sigma-1)}{n} .
$$

Clearly, $\partial \varepsilon / \partial \mathrm{n}=(\sigma-1) / \mathrm{n}^{2}$. It is important to stress that (2) does not depend on any approximations, but only on the Bertrand-Nash assumption and the equality of all prices in equilibrium. This result was noted in Helpman and Krugman (1985, p. 119), but their analysis assumes that $\varepsilon=\sigma$. For monopolistic competition, we must assume $\sigma>1$ in order to obtain the intuitive result that the elasticity of demand facing each firm increases as more varieties are added. The explanation is that while increasing the number of varieties lowers the income effect of a price change, this is more than offset by a relatively large substitution effect when $\sigma>1$. Note that the firm will believe, from (1), that 
$\partial \varepsilon_{\mathrm{i}} / \partial \mathrm{p}_{\mathrm{i}}>0$. However, in comparing symmetrical Nash equilibria, it is only necessary to examine (2), where $\partial \varepsilon / \partial p=0$. Between Nash equilibria all prices rise or fall and so the elasticity of demand depends only on the number of varieties.

There is free entry of new varieties, each of which enters the utility function in precisely the same way. In the free-entry equilibrium, ignoring the integer problem, the price of every variety must be the same and equal to its cost of production. The Nash solution for the model then consists of three equations:

$$
\begin{aligned}
& p=\frac{\varepsilon(n) \beta}{[\varepsilon(n)-1]}=\frac{\beta(n-\alpha)}{\theta(n-1)} \\
& p=\frac{\alpha}{x}+\beta \\
& L=n(\alpha+\beta x) .
\end{aligned}
$$

The profit-maximization equation (3) has been written in two ways: the first way is the familiar one; the second way is critical to our formulation and takes account of (2) and the definition $\sigma=1 /(1-\theta) .^{3}$ Equation (4) is the free entry condition, and equation (5) is full employment.

We make two observations. First, if one makes the DSK approximation, the elasticity of demand $\varepsilon$ is a constant and so the price of each variety, $p$, is fixed. It follows from (4) that output, $x$, of each variety is also fixed, so that as the population increases, per capita consumption of each variety must fall. In

\footnotetext{
${ }^{3}$ Note from (3) that as $n$ goes to infinity, the price goes to $\beta / \theta$ instead of just $\beta$ in contrast to Cournot oligopoly. Roy Ruffin (1971) shows that in the Cournot case, with a U-shaped cost curve, an exogenous increase in the number of firms (if viable) results in price approaching marginal cost, but for an endogenous increase (with free entry) due to a larger market price approaches minimum average cost.
} 
the more general case we present here, when the population rises, the number of varieties rises, which increases the elasticity of demand and drops the price, so output must rise, but not by as much as the population, so that per capita consumption again falls.

The second observation is that the equations may be easily generalized to any number of industries just by indexing the variables. Krugman (1981) builds on this observation to use the model to explain the volume of intra-industry trade. We later show how the observation affects the measurement of real income.

We can now offer a more accurate graphical presentation of the model than that found in Krugman (1979). In Figure 1, the curve PP shows the "price" equation (3). It is downward-sloping because with more varieties, individual firms face more competition from substitutes and must lower their price to maximize profits. Equations (4) and (5) can be collapsed into a single equation by eliminating $x$ so that average cost is a function of the size of the labor force and the number of varieties.

$$
p=\frac{n \alpha \beta}{(L-n \alpha)}+\beta
$$

Thus, an increase in the number varieties, $n$, must cause the price, or average costs, to rise. In Figure 1, this "cost" equation (6) is labeled CC. Intuitively, this is easy to understand because from (5) we can see that for a constant $L$, an increase in $n$ must depress $x$, the output of each firm, to maintain full 
employment; but if $x$ falls, due to economies of scale, equation (4) tells us that $p$ or average costs will rise.

An increase in $L$ shifts the CC curve to the right and, thus, increases $n$ and lowers $p$. Thus, since $p$ falls, it must be that the output of each commodity, $x$, rises. This representation is consistent with the usual monopolistic competition story that an increase in the population moves the economy down each average cost curve, as noted above.

The effect of globalization is shown by assuming that there is a foreign country (indicated by an *) facing the same costs and with the same demand. In Figure 1, we assume that $\mathrm{L}^{*}>\mathrm{L}$, so that the cost equation for the foreign country is shifted to the right but with the same price equation. The world economy is indicated by the $\mathrm{C}^{\circ} \mathrm{C}^{\circ}$ curve reflecting the even higher world labor supply of $L^{*}+L=L^{\circ}$. Clearly, free trade benefits the smaller "home" country more than the larger foreign country.

\section{Quantitative analysis}

It is not necessary to analyze equations (3)-(5) by the standard comparative statics because we can solve for $x, n$, and $p .^{4}$ These will be critical in answering the questions with which we started this paper. To proceed, equation (5) can be

\footnotetext{
${ }^{4}$ For completeness, differentiating (3)-(5) yields: $\partial p / \partial L=-\varepsilon^{\prime}(p-\beta) / \Delta, \partial x / \partial L=x \varepsilon^{\prime} / \Delta$, and $\partial n / \partial L=(\varepsilon-1) / \Delta L$, where $\Delta=\left[(\varepsilon-1) L / n+\varepsilon^{\prime} n \beta x\right]>0$.
} 
substituted into (4) to eliminate $x$, and then (4) can be equated to (3) to solve for $n$. In turn, we can solve for the reduced form solutions:

$$
\begin{aligned}
& x=\frac{\alpha \theta(L-\alpha)}{\beta[L(1-\theta)+\alpha \theta]} \\
& n=\frac{[L(1-\theta)+\alpha \theta]}{\alpha} \\
& p=\frac{\beta L}{\theta(L-\alpha)} .
\end{aligned}
$$

Notice that the term $(L-\alpha)$ appears in two of these equations. The interpretation is that for the model to make any sense, the labor supply of the economy must exceed the fixed cost of producing a single variety.

From the standpoint of international trade theory, equation (9) is the most interesting. It shows that the fall in the price of the product as the labor supply increases is fairly gradual because $\partial[L /(L-\alpha)] / \partial L=-\alpha /(L-\alpha)^{2}$, but is proportional to the magnitude of marginal costs relative to the inverse preference for variety, $\theta$. This gives us an explanation of the evolution of comparative advantage between economies with high and low marginal costs. Economies producing lots of different goods with low marginal costs will find that being larger does not lower their prices as much as economies with high marginal costs. Population growth in the United States might lower prices less than population growth in, say, India or China. Thus, faster growth can shift comparative advantage in differentiated products in favor of such countries.

Since it is the ratio $\beta / \theta$ that matters, we can see that the preference for variety (a low $\theta$ ) also plays a role in determining the course of comparative 
advantage. It is difficult to solve the model with differences in technology, however, and we leave this matter aside for future work.

Per capita consumption of each variety is $c=x / L$. It is convenient to define $A=L(1-\theta)+\alpha \theta$. Thus

$$
c=\frac{\alpha \theta(L-\alpha)}{\beta A L} .
$$

It is clear that as $L$ increases, per capita consumption of each variety falls. This is a prediction of the model. Recall that Krugman (1979) obtained this result by assuming that the elasticity of demand rises with smaller consumption. This was necessary because a greater population had to lead firms to lower their price as they faced a higher price elasticity of demand. However, we now have derived this result as a testable prediction rather than an assumption.

The quantity $x n$ is "real" GDP. GDP is $p x n=(\alpha / x+\beta) x n=n(\alpha+\beta x)=L$ by (5). Thus, "real" GDP is $L / p$ while per capita real GDP is simply:

$$
y=\frac{1}{p}=\frac{\theta(L-\alpha)}{\beta L} .
$$

From the utility function, the utility of each consumer is $u=n^{\frac{1}{\theta}} c$. Per capita utility (real income) is thus:

$$
u=\left(\frac{A}{\alpha}\right)^{\frac{1-\theta}{\theta}} y .
$$

Equation (12) shows that $u / y$ is increasing in the labor supply, since $A=L(1-\theta)$ $+\alpha \theta$. The larger an economy, the greater is the departure of the measurement of real income from the measurement of per capita real GDP. In other words, GDP 
was a better measure of well-being in the year 1900 than in 2000! Note that $A / \alpha$ is raised to the power $(1-\theta) / \theta$, which is a good measure of the preference for variety. As the preference for variety increases, the coefficient of per capita income rises; as the preference for variety vanishes $(\theta=1)$, utility equals per capita income. From the definition of $A$, and noting equation (8), the ratio $A / \alpha$ is simply the number of varieties.

It is not necessary to assume a single good with different varieties. Assume now many industries with labor perfectly mobile between industries as well as varieties..$^{5}$ Recall our observation that the basic equations are the same for each industry. If we make the assumption that the overall utility function is CobbDouglas in the sub-utility functions given by the CES utility functions, with possibly different $\theta$ s, it is easy to generalize (12) for any number of industries with per capita income measured for each industry. The natural log of such a Cobb-Douglas utility function is:

$$
\ln u=\sum_{i}\left\{\gamma_{i} \frac{\left(1-\theta_{i}\right)}{\theta_{i}} \ln \left(\frac{A_{i}}{\alpha_{i}}\right)+\gamma_{i} \ln y_{i}\right\},
$$

where $\gamma_{i}$ is the share spent on good $i, \theta_{i}$ is the preference parameter for varieties of the $\mathrm{i}^{\text {th }}$ good, and $A_{i}=L_{\mathrm{i}}\left(1-\theta_{i}\right)+\alpha_{i} \theta_{i}$. Note that $y_{i}$ is now per capita income in sector i measured in terms of good $i$, or $y_{i}=\theta_{\mathrm{i}}\left(\gamma_{\mathrm{i}} L-\alpha\right) / \beta_{\mathrm{i}} \gamma_{\mathrm{i}} \mathrm{L}$, using (11) and $L_{i}$ $=\gamma_{i} L$.

\footnotetext{
${ }^{5}$ Krugman (1981) assumes labor cannot move between industries, but can between varieties.
} 
This equation tells us the following. ${ }^{6}$ Even in a world of no measurement problems with completely homogeneous labor, the real income (utility) of a community cannot be measured without looking at (1) the share spent on each industry, (2) the desire for variety in each industry, (3) the resources devoted to each industry relative to fixed costs, and (4) the per capita output of each industry. In other words, a measure such as GDP covers up a lot of sins, and "micro" data are necessary to yield macro answers. This finding, of course, follows from our very simple model; but presumably in a more complicated model, the situation might even be worse.

Consider a back-of-the-envelope calculation of the gains from variety. Suppose, for example, that there are but two sectors of the economy. Sector 1 has a $\sigma_{1}=\infty$. Thus:

$$
\ln u=\gamma_{1} \ln y_{1}+\gamma_{2}\left[\frac{1-\theta_{2}}{\theta_{2}}\right] \ln n_{2}+\gamma_{2} \ln y_{2} .
$$

The middle term captures the impact of variety. Suppose, along with Broda and Weinstein (2006) that we assume the median elasticity of substitution is 2.7. Since $(1-\theta) / \theta=1 /(\sigma-1)=1 / 1.7=.59$. If $\gamma_{2}=.5$, so half of all goods are variety goods, then a 1 percent rate of growth in variety per year (Bils and Klenow, 2001) would increase real income by $.5(.59)=.3$ percent per year. Triple the rate of growth in variety and the contribution of variety to real income growth would

\footnotetext{
${ }^{6}$ How equation (13) would be modified by the production structure in which the increased variety of inputs expands the output of a homogeneous good is an interesting question we have not pursued (see Wilfred J. Ethier, 1982).
} 
be to add about 1 percent per year to the rate of growth in real income. Cox and Alm (1998) showed that in consumer packaged goods alone, producers introduced 24,965 new goods in 1998, up from just 4,414 in $1980 .^{7}$ Thus, it is very critical to get more accurate estimates of the relevant parameters.

\section{Globalization}

Let us now return to the single sector case and consider what happens when you have globalization. We have just seen that the growth of variety may on an annual basis raise real income modestly but perhaps very significantly. In standard trade theory, the movement from autarky to free trade has a very modest effect on real income. What happens in the case of the DSK model? We show that this effect is far from modest.

With free trade, identical technologies, identical preferences, and zero costs of transferring goods, the world economy works like one large economy. In Figure 1, the cost curve for the world economy is $\mathrm{C}^{\circ} \mathrm{C}^{\circ}$, which lies to the right of the foreign $\mathrm{C}^{*} \mathrm{C}^{*}$. The equation the world cost curve $\mathrm{C}^{\circ} \mathrm{C}^{\circ}$ is now similar to Equation (6):

$$
p=\frac{\left(n+n^{*}\right) \alpha \beta}{L+L^{*}-\left(n+n^{*}\right) \alpha}+\beta .
$$

The joint number of varieties is now $\left(n+n^{*}\right)$. We can see in Figure 1 but also by general reasoning that the free trade level of output for each firm, $\mathrm{x}^{\circ}$ will

\footnotetext{
${ }^{7}$ Retailers code and track new product introductions in terms of shelf-keeping units (SKUs). While surely many new product introductions fail, many also remain-if consumers want them.
} 
exceed the autarkic levels, $x$ and $x^{*}$ simply because the price of the product is smaller. Since it is still true that $L=n(\alpha+\beta x)$, the larger output means the number of varieties each country produces in free trade must fall short of the number of varieties produced under autarky. Note that with free entry and exit which varieties are produced by which country cannot be determined. To the extent that comparative advantage is not involved, the pattern of trade is indeterminate. When economies of scale are involved, who exports what can be determined by the accident of history.

In our free trade world every consumer has the same real income and consumption of each variety. Letting $L^{\circ}=L+L^{*}$ and $A^{\circ}=L^{\circ}(1-\theta)+\alpha \theta$, all the solutions (7), (8), (9), (11), and (12) are exactly the same, but with $\mathrm{L}^{\circ}$ and $\mathrm{A}^{\circ}$ instead of $L$ and $A$. In the entire world, per capita income is $y^{\circ}=\theta\left(L^{\circ}-\alpha\right) / \beta L^{\circ}$. Accordingly, the ratio of per capita income in free trade to per capita income in autarky is simply:

$$
\frac{y^{o}}{y}=\frac{L\left(L^{o}-\alpha\right)}{L^{o}(L-\alpha)}>1 .
$$

This can be rewritten as:

$$
z=\frac{\left(1-\frac{\alpha}{L^{o}}\right)}{\left(1-\frac{\alpha}{L}\right)}
$$

But any reasonable estimate of $\alpha / \mathrm{L}$ or $\alpha / \mathrm{L}^{\circ}$ need not be very small. It would be similar to the ratio of fixed costs of an average business firm to the size of the industry. For example: About $\$ 100$ billion of value-added is in the U.S. 
automobile industry; GM annual sales are about $\$ 180$ billion, so it is reasonable to suppose fixed costs in the neighborhood of $\$ 30$ billion. Thus, provisionally, assume $\alpha / \mathrm{L}$ is 0.3 while $\alpha / \mathrm{L}^{\circ}$ is 0.1 . Then the ratio would be $\mathrm{z}=.9 / .7=1.28$ not an unreasonable estimate. Accordingly, the gain in productivity for each firm or industry due to economies of scale should be significant. Of course, we must remember we are here considering a move from autarky to free trade, not a movement toward more trade such as the North American Free Trade Agreement. Nonetheless, the fact that it has been difficult to observe the gains from trade due to economies of scale (Daniel Trefler, 2004, p. 887; Kieth Head and John Ries, 1999) should be regarded as a puzzle to be sorted out.

Using (12), the ratio of free trade utility to autarky utility is:

$$
\frac{u^{o}}{u}=\left(\frac{A^{o}}{A}\right)^{\frac{1-\theta}{\theta}} \frac{y^{o}}{y} .
$$

This shows that the increase in utility could be a substantial multiple of the increase in per capita income. For example, if the home country was only $10 \%$ of the world, $\mathrm{A}^{\circ} / \mathrm{A} \approx 10$ and if $\theta=.4$ the proportionate increase in utility would be more than ten times the proportionate increase in per capita income. But as the inverse measure of the preference for variety goes to 1 , the gains from trade simply reflects the change in per capita income. This seems to be an order of magnitude too large for the gains from trade, and the explanation would undoubtedly involve a higher $\theta$ and taking into account trade costs and the relative importance of intra-industry trade. But it does suggest that better 
estimates of $\theta$ might be useful. Notice that the effect of the increase in variety brought about by globalization may be much larger than any impact on productivity in this world without comparative advantages.

Equation (15) captures the tension between economies of scale and the number of varieties. The greater are the economies of scale, the smaller is $\mathrm{A}^{\circ} / \mathrm{A}$ and the larger is $\mathrm{y}^{\circ} / \mathrm{y}$.

This tension is of course absent in the approximation used by Dixit and Stiglitz (1977) and Krugman (1981). When one sets $\varepsilon=\sigma=1 /(1-\theta)$, then the solutions to (3)-(5) are easy:

$$
\begin{aligned}
& p=\frac{\beta}{\theta} \\
& x=\frac{\alpha \theta}{\beta(1-\theta)} \\
& n=\frac{L(1-\theta)}{\alpha} .
\end{aligned}
$$

Now per capita income is a constant, $\theta / \beta$, so any changes in the labor supply or trade cannot change $p$, per capita income, or $x$. All that happens is that the number of varieties increases. International trade would then have the impact of $\frac{u^{o}}{u}=\left(\frac{L^{o}}{L}\right)^{\frac{1-\theta}{\theta}}$.

\section{Social efficiency}


We now want to show that the degree of economies of scale does not appear to be significant in determining the social efficiency of the market equilibrium. The socially efficient number of firms is formed by maximizing:

$$
H=n^{\frac{1}{\theta}} c+\lambda[L-n(\alpha+\beta x)]
$$

In other words, we are maximizing per capita utility subject to the resource constraint. Since $c=x / L$, we can rewrite (20) as:

$$
H=n^{\frac{1}{\theta}}\left(\frac{x}{L}\right)+\lambda[L-n(\alpha+\beta x)]
$$

The function $\mathrm{n}^{1 / \theta} \mathrm{x}$ is quasi-concave, so $\mathrm{H}$ is maximized when $\mathrm{x}$ and $\mathrm{n}$ are selected so that:

$$
\begin{aligned}
& \frac{\partial H}{\partial n}=n^{\frac{1}{\theta-1}}\left(\frac{x}{\theta L}\right)-\lambda\left(\frac{L}{n}\right)=0 \\
& \frac{\partial H}{\partial x}=\frac{n^{\frac{1}{\theta}}}{L}-\lambda n \beta=0 \\
& \frac{\partial H}{\partial \lambda}=L-n(\alpha+\beta x)=0 .
\end{aligned}
$$

Fortunately, we can eliminate $n^{\frac{1}{\theta}}$ from (22) and (23) and solve for the social optimum, $n^{\text {opt }}$.

$$
n^{o p t}=\frac{L(1-\theta)}{\alpha} .
$$

But from (8) it is clear that the private equilibrium is $n=n^{\text {opt }}+\theta$. The social optimum falls short of the private equilibrium by just a fraction, $\theta$, and, thus, social efficiency holds approximately in the private equilibrium. The reason 
economies of scale do not matter in the question is that such economies affect both $n$ and $n^{\text {opt }}$ equally.

\section{Conclusions}

This paper explores the implications of allowing the number of varieties in the Dixit-Stiglitz-Krugman model of monopolistic competition to affect the elasticity of demand facing each firm. While the difference between the elasticity of substitution and the elasticity of demand may be slight, the results show that:

1. The utility of each person depends on not only the amount of variety, but on the per capita income or efficiency of the economy. In a multi-sector set-up, utility per capita reflects the elasticity of substitution in each sector, the share of income devoted to each sector, and the value-added of each sector. This gives one a different view of real income than a simple GDP calculation.

2. Abstracting from comparative advantage, the gains from globalization can be divided into the gain from variety and the gain from economies of scale. There is, however, a tension between them because greater economies of scale reduce the gains from variety. The gains from the latter appear to be larger.

3. An interesting extension might be to show the relative importance of economies of scale and differences in productivity among domestic and 
exporting firms (Melitz, 2003; Feenstra and Kee, 2008). How to do this remains a puzzle because a continuum of firms simplifies the model but necessarily abstracts from economies of scale.

4. Free entry does not result in significant socially inefficient entry. This is because economies of scale equally affect the market equilibrium number of firms and the socially efficient number. 


\section{References}

d'Aspremont , Claude, Rodolphe Dos Santos Ferreira, and Louis-André GérardVaret. 1996. "On the Dixit-Stiglitz Model of Monopolistic Competition," American Economic Review, 86, pp. 623-29.

Bils, Mark and Peter Klenow. 2001. "The Acceleration of Variety Growth," American Economic Review, 41, pp. 274-280.

Broda, Christian and David E. Weinstein. 2006. "Globalization and the Gains from Variety," Quarterly Journal of Economics, 121 (2), pp. 541-585.

Cox, W. Michael and Richard Alm. 1998. "The Right Stuff: America's Move to Mass customization," 1998 Annual Report, Federal Reserve Bank of Dallas, pp. $3-26$.

Dixit, Avinash K. and Joseph Stiglitz. 1977. "Monopolistic Competition and Optimum Product Diversity." American Economic Review, 67 (3), pp. 297-308.

Dixit, Avinash K. and Victor D. Norman. 1980. Theory of International Trade. Digswell Place: Cambridge University Press. 
Dollar, D. and F. Rodriguez. 2001. "Trade Policy and Economic Growth: A Skeptic's Guide to the Cross-Country Evidence," Brookings Economic Papers.

Ethier, Wilfred J. 1982. "National and International Returns to Scale in the Modern Theory of International Trade," American Economic Review, 72, pp. 389405.

Feenstra, Robert. 1994. "New Product Varieties and the Measurement of International Prices," American Economic Review, 84, pp. 157-177.

Feenstra, Robert and Hiau Looi Kee. 2008. "Export Variety and Country Productivity: Estimating the Monopolistic Competition Model with Endogenous Productivity." Journal of International Economics, 74, 500-518.

Head, Kieth and John Ries. 1999. "Rationalization Effects of Tariff Reductions," Journal of International Economics. 47 (2), pp. 295-320.

Helpman, Elhanan. and Paul Krugman. 1985. Foreign Trade and Market Structure. Cambridge: MIT Press. 
Krugman, Paul R. 1979. "Increasing returns, monopolistic competition and international trade." Journal of International Economics, 9 (4), pp. 469-479.

Krugman, Paul R. 1981. "Intraindustry Specialization and the Gains From Trade," Journal of Political Economy, 89, pp. 253-266.

Lancaster, Kelvin. 1980. "Intra-industry Trade under Perfect Monopolistic Competition," Journal of International Economics, 10, 151-176.

Mankiw, N. Gregory and Michael D. Whinston. 1986. "Free Entry and Social Inefficiency," Rand Journal of Economics, 17, pp. 48-58.

Melitz, Marc. 2003. "The Impact of Trade on Intra-Industry Reallocations and Aggregate Productivity," Econometrica, 71, 1695-1725.

Montagna, Catia. 2001. "Efficiency Gaps, Love of Variety, and International Trade," Economica, 68 (269), pp.27-44.

Ruffin, Roy J. 1971. "Cournot Oligopoly and Competitive Behavior," Review of Economic Studies, 38, pp. 493-502. 
Samuelson, Paul. 1948. Economics. New York: McGraw-Hill.

Samuelson, Paul. 1967. Economics, $7^{\text {th }}$ Edition, New York: McGraw-Hill.

Trefler, Daniel. 2004. "The Long and the Short of the Canada-U.S. Free Trade Agreement," American Economic Review, 94 (4), pp. 870-895.

Yang, Xiaokai and Ben J. Heijdra. 1993. "Monopolistic Competition and Optimum Product Diversity: Comment," American Economic Review, 83, pp. 295-301.

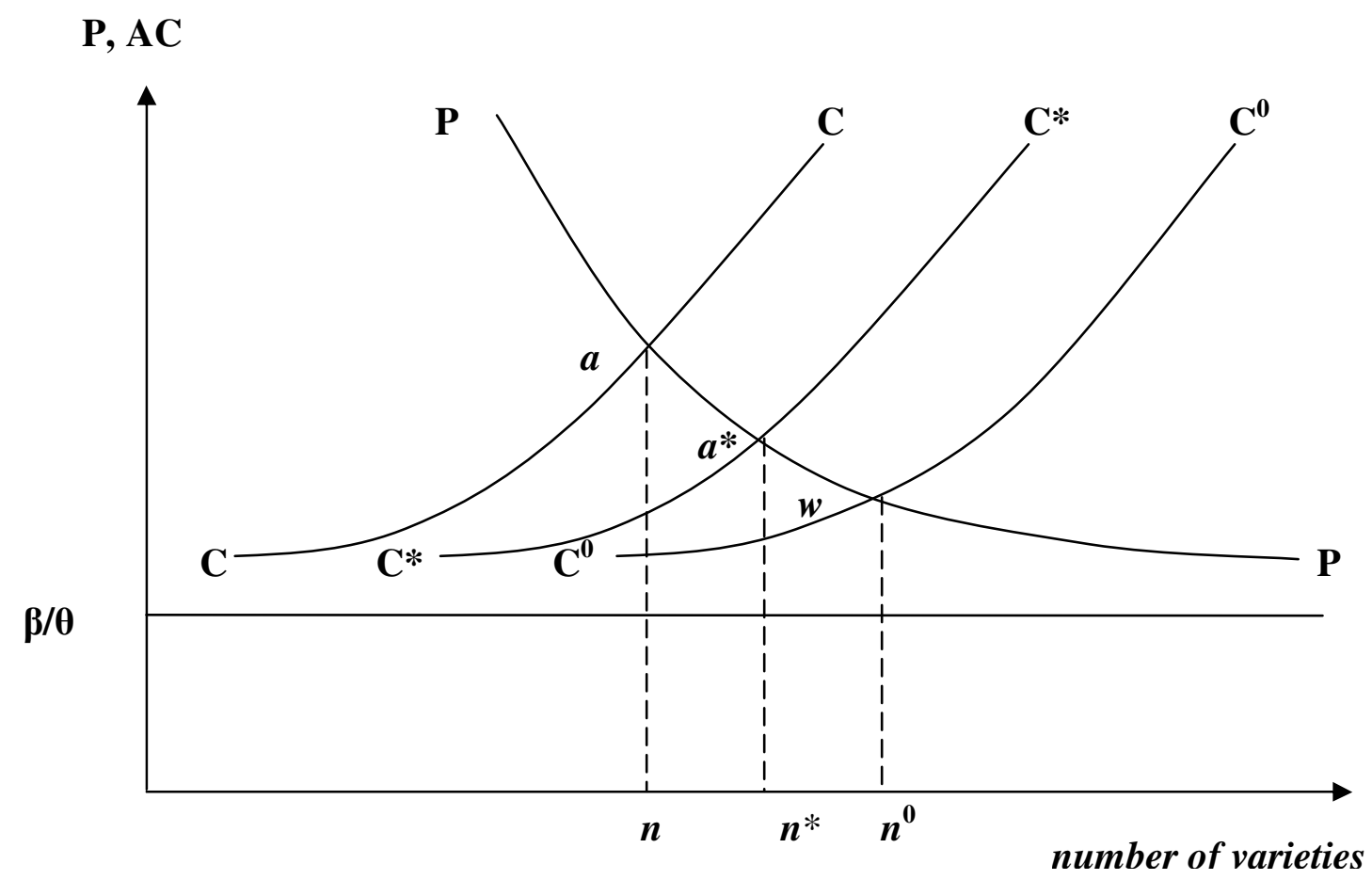

Figure 1 